\title{
Prevalence of menopausal symptoms and its association with various factors among women in post menopausal age group: a cross-sectional study
}

\author{
Sushree Priyadarsini Satapathy ${ }^{1}$, Nivedita Karmee ${ }^{2 *}$, Rabinarayan Dash ${ }^{3}$
}

\author{
${ }^{1}$ Department of Community Medicine, VIMSAR, Burla, Odisha, India \\ ${ }^{2}$ Department of Community Medicine, MKCG, MCH, Berhampur, Odisha, India \\ ${ }^{3}$ Department of Obstetrics and Gynaecology, BBMCH, Bolangir, Odisha, India
}

Received: 18 July 2020

Accepted: 14 August 2020

\section{*Correspondence:}

Dr. Nivedita Karmee,

E-mail: niveditakarmee@yahoo.com

Copyright: (C) the author(s), publisher and licensee Medip Academy. This is an open-access article distributed under the terms of the Creative Commons Attribution Non-Commercial License, which permits unrestricted non-commercial use, distribution, and reproduction in any medium, provided the original work is properly cited.

\begin{abstract}
Background: Menopause is an important time in women's life and it is a natural event in the process of aging. The onset of menopause heralds a time of diminished estrogen exposure, which may have both acute and chronic effect on health and quality of life.

Methods: It was a cross sectional study, conducted for a period of 3months i.e. June to August 2018 among post menopausal women in 8 selected villages with a sample size of 247.

Results: The common post- menopausal symptoms were joint and muscular discomfort, bladder problems, symptoms of dryness of vagina, physical and mental exhaustion. Factors like education, occupation, socio-economic status, marital status, parity, mode of delivery, age at menopause and BMI was related to one or more menopausal symptoms.

Conclusions: Proper and timely intervention among post menopausal women will help to reduce the symptoms and lead a better quality of life.
\end{abstract}

Keywords: Postmenopausal women, Menopausal symptoms, Determinants

\section{INTRODUCTION}

The term "menopause" is commonly used to describe any of the changes a woman experiences either just before or after she stops menstruating, marking the end of her reproductive period. Menopause is cessation of periods for 12 months or cessation of ovarian function resulting in permanent amenorrhoea. ${ }^{1}$

As per WHO (1996), there were an estimated 467 million women in peri-menopause state in 1990 and this number is expected to increase 1200 million by the year $2030 .^{2}$ Out of these, $76 \%$ will be living in the developing countries. ${ }^{3}$
India has a large population which has already crossed the 1.2 billion mark with 72 million people over 60 years of age and the number of menopausal women being about 43 million. Average age of menopause is 47 years in Indian women with average life expectancy of 71 years. ${ }^{4}$

During this transition period, women experience different symptoms, like physical disturbances (hot flashes) and psychological complaints (mood swings). Most of women in India, do not understand these symptoms and changes taking place in life, and spend their valuable life battling these problems and associated diseases.

The individual experience of the menopause transition varies widely. Important influential factors include the 
age at which menopause occurs, personal health and wellbeing, and each woman's socio-demographic, environment and culture. ${ }^{5}$

While women of reproductive age group (15-45 years) are covered under the reproductive and child health $(\mathrm{RCH})$ program, the postmenopausal women ageing 45 and above are not covered in any specific health program in the country. In Odisha very few studies have been conducted on the prevalence of menopausal symptoms and its associated factors among women in post menopausal age group in rural areas. With this backdrop a study was conducted with the following objectives: to find out the prevalence of menopausal symptoms among study population and to identify various determinants associated with it.

\section{METHODS}

It was a cross sectional community based observational study, conducted for a period of 3 months i.e. June to August 2018 among post menopausal women in the 8 selected villages of Chhatrapur block of Ganjam district, Odisha.

\section{Inclusion criteria}

The study population included all the women who had attained natural menopause and who had their last menstrual bleeding at least one year prior to the data collection. Women who gave consent for interviewing.

\section{Exclusion criteria}

Women who were in the transitional period of attaining menopause and those who had undergone hysterectomy due to any cause.

\section{Sample size}

Taking the prevalence(p) of hot flushes which is the most common postmenopausal symptom as $60.9 \%$; relative allowable error as $10 \%$ and confidence interval as $95 \%$, sample size was calculated using the formula, $(1.96)^{2} \mathrm{p}$ $\mathrm{q} / \mathrm{L}^{2}$. The sample size came out to be 247 .

\section{Sampling method}

Selection of blocks and villages was done using multistage random sampling method was used. Out of 22 blocks in Ganjam, Chhatrapur block was selected randomly using lottery method. Chhatrapur block consists of total 80 villages. $10 \%$ of the total villages i.e. 8 villages were selected by simple random sampling method using random number table.

Selection of desired number of post menopausal women from each villages was done using probability proportion to size sampling method(PPS), the required number of women in post menopausal group were taken from each village for the study purpose .At first villages were listed with the respective number of women population. The total female population of the selected villages was collected from the census $2011^{7}$ of the respective villages. Then cumulative population of women was calculated. From each village number of postmenopausal women to be included for the study was obtained by dividing the cumulative population of women to the total no of women population of that village multipled by sample size.

Desired no. of postmenopausal women required from each villages $=($ cumulative female population/women population of a village )*sample size. This gives the total no. of women to be included from each villages for our study purpose.

Selection of household: In the selected village a landmark preferably AWC or school, temple was taken as a central point and by spinning a bottle, the direction of the first lane was decided. First house of that lane was visited, if the eligible women was found it was considered to be the first household and starting from that particular household consecutive household were selected till the desired sample was obtained. If in case more than one eligible women were found then the women who was older was selected. If a house was locked or had no women in post menopausal age group or the women present were not willing to give consent, then the adjoining house was visited. The same procedure was used in selecting the households from all the 8villages, until the desired sample size was achieved.

\section{RESULTS}

Majority i.e. $95(38.4 \%)$ belonged to age group of 51$55 y e a r s$ and the mean age of the respondents was $52.20 \pm 4.377$ years with the minimum age being 43 years and maximum 64 years. $82.2 \%$ of post menopausal women were Hindus and $74.1 \%$ belonged to general category. Nearly $79.4 \%$ of the post menopausal were illiterate and $58.7 \%$ of the spouse was illiterate. Majority of post menopausal women i.e. $68.4 \%$ were home makers and $77.4 \%$ belonged to lower socioeconomic status. Most of respondents i.e. $46.6 \%$ were married and $56.3 \%$ of postmenopausal women lived in nuclear families. $59.1 \%$ were self dependent as far as daily activities was concerned.

The menopausal symptoms were grouped in three categories that is Somato-vegetative, psychological and urogenital symptoms. The prevalence of any one of the symptoms among the respondents was considered as presence of symptom. The most common symptom was somato-vegetative symptoms(78.5\%) in the present study.

Joint and muscular discomfort was the most frequent symptom found in $55.1 \%$ women among somatovegetative symptoms. Bladder problem, an urogenital 
symptom, which includes increase in frequency of urination followed by leakage of urine, pain while passing urine and inability to control urine was the most common complaint found in $63.41 \%$ of respondents , followed by symptoms dryness of vagina in $30.9 \%$ and $5.69 \%$ had sexual problems. Among the psychological symptoms, physical and mental exhaustion was the chief symptom among the postmenopausal women i.e. $54.1 \%$ followed by irritability in $27.1 \%$, depression in $15.9 \%$, and anxiety in $2.9 \%$.

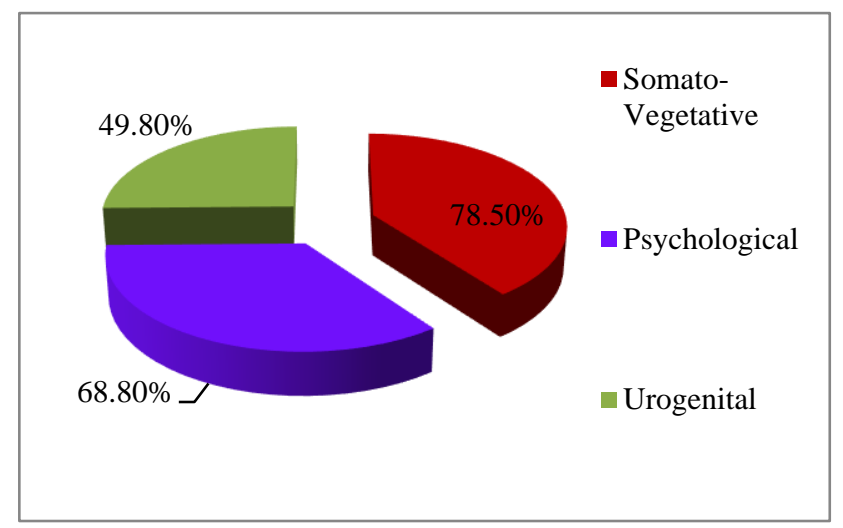

Figure 1: Prevalence of menopausal symptoms.

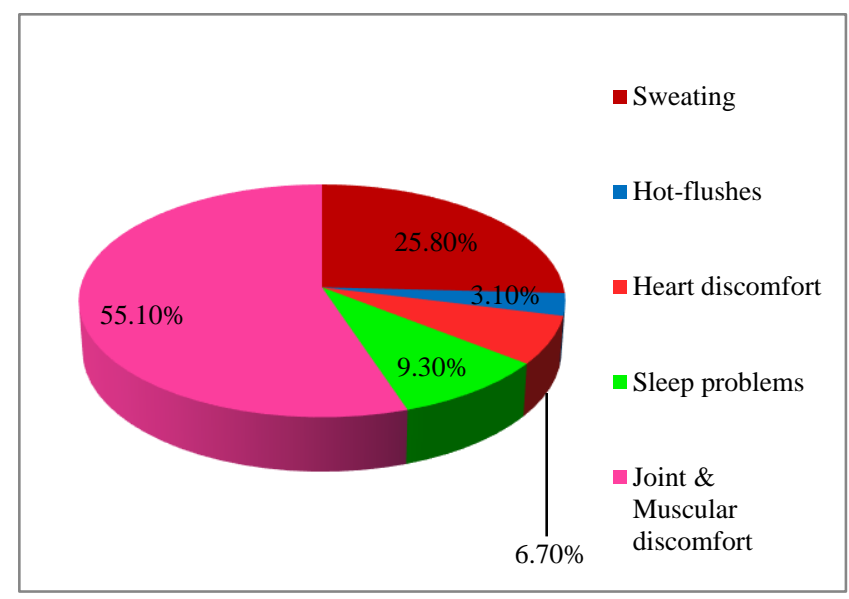

Figure 2: Prevalence of somato-vegetative symptoms.

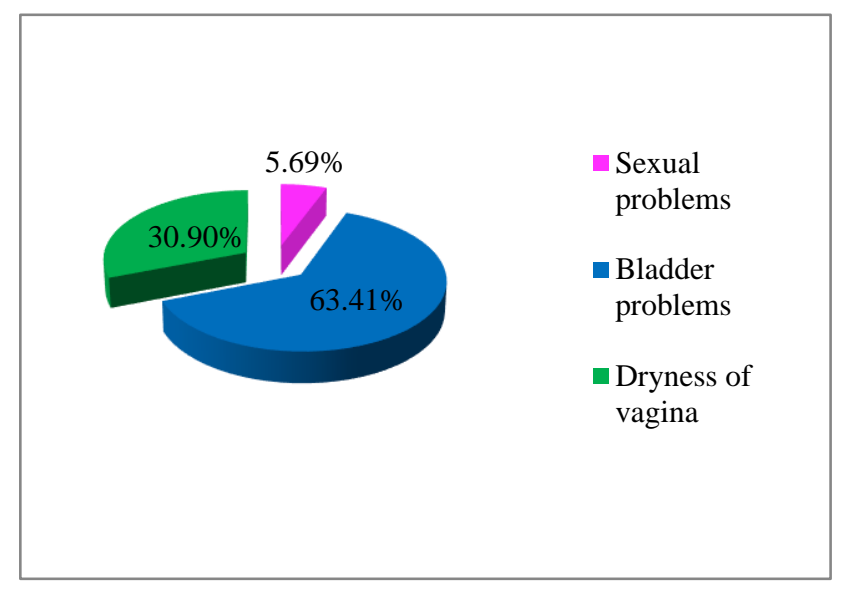

Figure 3: Prevalence of urogenital symptoms.

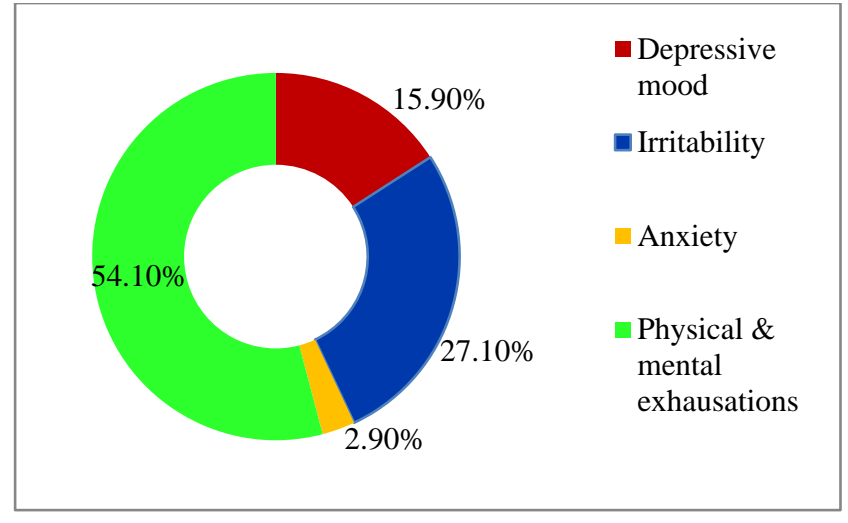

Figure 4: Prevalence of psychological symptoms.

Highest proportion of somato-vegetative symptoms was seen in the women who were illiterate $(83.7 \%)$ compared to women who were literate. More number of home makers $(82.2 \%)$ complained of somato vegetative symptoms compared to working women. Most of the women i.e. $93.4 \%$ who were in lower class had comparatively more symptoms than those who were in upper and middle class. Association of sociodemographic factors like education( $\mathrm{p}=0.001)$, occupation $(p=0.037)$ and socio-economic status $(p<0.001)$ with the somato-vegetative symptoms were found to be statistically significant.

The proportion of somato-vegetative symptoms was more i.e. $100 \%$ in unmarried women compared to married women and this difference between marital status and presence of somatic symptoms was statistically significant with $\mathrm{p}=0.005$. Respondents having children had more symptoms compared to nulliparous women and the association between parity and somato-vegetative symptoms was found to be statistically significant with $\mathrm{p}<0.001$.

Postmenopausal women who were married i.e. $60.4 \%$ had more urogenital symptoms compared to unmarried women and the marital status and presence of urogenital symptoms had significant difference with $\mathrm{p}=0.002$. Respondents who had more than 3 children or had normal delivery complained of more urogenital symptoms compared to women who had no children or had caesarean section and the relationship between factors like parity $(\mathrm{p}=0.038)$ and mode of delivery with the presence of urogenital symptoms was found to be statistically significant $(\mathrm{p}=0.0005)$.

In the present study it was found that women living in nuclear families(77\% ) and those who were dependent on self for daily activities had more psychological symptoms $(95.2 \%)$ in comparison to those living in joint families and those who dependent on their spouse or family members. This association between the nature of dependency $(\mathrm{p}<0.001)$ and type of family $(\mathrm{p}=0.002)$ with the presence of psychological symptom was found to be statistically significant. 
Table 1: Association of socio-demographic factors with somato-vegetative symptoms.

\begin{tabular}{|c|c|c|c|c|}
\hline \multirow{2}{*}{ Variables } & \multicolumn{2}{|c|}{ Somato-vegetative symptoms } & \multirow{2}{*}{ Total $(\%)$} & \multirow{2}{*}{$\begin{array}{l}\text { Chi-square } \\
\text { P value }\end{array}$} \\
\hline & Yes $(\%)$ & No $(\%)$ & & \\
\hline \multicolumn{5}{|l|}{ Education } \\
\hline Illiterate & $164(83.7)$ & $32(16.3)$ & $196(100)$ & \\
\hline Primary & $24(63.2)$ & $14(36.8)$ & $38(100)$ & $X^{2=}=16.871$ \\
\hline Secondary & $5(50)$ & $5(50)$ & $10(100)$ & $\mathrm{p}=0.001 *$ \\
\hline Higher secondary \& above & $1(33.3)$ & $2(66.7)$ & $3(100)$ & \\
\hline Total & $194(78.5)$ & $53(21.5)$ & 247 & \\
\hline \multicolumn{5}{|l|}{ Occupation } \\
\hline Home-maker & $139(82.2)$ & $30(17.8)$ & $169(100)$ & \\
\hline $\begin{array}{l}\text { Working Women } \\
\text { (Agricultural + labourer) }\end{array}$ & $55(70.5)$ & $23(29.5)$ & $78(100)$ & $\begin{array}{l}X^{2}=4.361 \\
p=0.037^{*}\end{array}$ \\
\hline Total & $194(78.5)$ & $53(21.5)$ & 247 & \\
\hline \multicolumn{5}{|l|}{ Socio-economic status } \\
\hline Upper & $0(0)$ & $2(100)$ & $2(100)$ & \\
\hline Upper-middle & $2(18.2)$ & $9(81.8)$ & $11(100)$ & \\
\hline Middle & $25(58.1)$ & $18(41.9)$ & $43(100)$ & $\mathrm{X} 2=53.367$ \\
\hline Lower-middle & $96(83.5)$ & $19(16.5)$ & $115(100)$ & $\mathrm{p}<0.001^{*}$ \\
\hline Lower & $71(93.4)$ & $5(6.6)$ & $76(100)$ & \\
\hline Total & $194(78.5)$ & $53(21.5)$ & 247 & \\
\hline
\end{tabular}

Table 2: Association of various factors with Somato-vegetative symptoms.

\begin{tabular}{|c|c|c|c|c|}
\hline \multirow{2}{*}{ Variables } & \multicolumn{2}{|c|}{ Somato-vegetative symptoms } & \multirow{2}{*}{ Total $(\%)$} & \multirow{2}{*}{$\begin{array}{l}\text { Chi-square } \\
\text { P value }\end{array}$} \\
\hline & Yes $(\%)$ & No $(\%)$ & & \\
\hline \multicolumn{5}{|l|}{ Marital status } \\
\hline Unmarried & $5(100)$ & $0(0)$ & $5(100)$ & $X^{2}=12.669$ \\
\hline Widow & $86(88.7)$ & 11(11.3) & $97(100)$ & $\mathrm{p}=0.005^{*}$ \\
\hline Divorced/separated & $5(83.3)$ & $1(16.7)$ & $6(100)$ & \\
\hline Married & $98(70.5)$ & $41(29.5)$ & $139(100)$ & \\
\hline Total & $194(78.5)$ & $53(21.5)$ & 247 & \\
\hline \multicolumn{5}{|l|}{ Parity } \\
\hline 0 & $3(33.3)$ & $5(66.7)$ & $9(100)$ & $X^{2}=47.664$ \\
\hline $1-2$ & $33(53.2)$ & $29(46.8)$ & $62(100)$ & $\mathrm{p}<0.001^{*}$ \\
\hline$>3$ & $158(78.5)$ & $18(10.2)$ & $176(100)$ & \\
\hline Total & $194(78.5)$ & $53(21.5)$ & 247 & \\
\hline
\end{tabular}

Table 3: Association of various factors with urogenital symptoms.

\begin{tabular}{|c|c|c|c|c|}
\hline \multirow{2}{*}{ Variables } & \multicolumn{2}{|c|}{ Urogenital symptoms } & \multirow{2}{*}{ Total (\%) } & \multirow{2}{*}{$\begin{array}{l}\text { Chi-square } \\
\text { P value }\end{array}$} \\
\hline & Yes (\%) & No (\%) & & \\
\hline \multicolumn{5}{|l|}{ Marital status } \\
\hline Married & $84(60.4)$ & $55(39.6)$ & $139(100)$ & $X^{2}=14.957$ \\
\hline Widow & $36(37.1)$ & $61(62.9)$ & $97(100)$ & $\mathrm{p}=0.002^{*}$ \\
\hline Divorced/separated & $2(33.3)$ & $4(66.7)$ & $6(100)$ & \\
\hline Unmarried & $1(20)$ & $4(80)$ & $5(100)$ & \\
\hline Total & $123(49.8)$ & $124(50.2)$ & 247 & \\
\hline \multicolumn{5}{|l|}{ Parity } \\
\hline 0 & $2(22.2)$ & $7(77.8)$ & $9(100)$ & $X^{2}=6.551$ \\
\hline $1-2$ & $25(40.3)$ & $37(59.7)$ & $62(100)$ & $\mathrm{p}=0.038^{*}$ \\
\hline$>3$ & $96(54.5)$ & $80(45.5)$ & $176(100)$ & \\
\hline Total & $123(49.8)$ & $124(50.2)$ & 247 & \\
\hline \multicolumn{5}{|l|}{ Mode of delivery } \\
\hline Normal & $116(94.3)$ & $91(43.9)$ & $207(100)$ & $\mathrm{X}^{2}=12.086$ \\
\hline Caesarean section & $7(22.6)$ & $24(77.4)$ & $31(100)$ & $\mathrm{p}=0.0005^{*}$ \\
\hline Total & $123(49.8)$ & $115(50.2)$ & 238 & \\
\hline
\end{tabular}


Table 4: Association of socio-demographic factors with psychological symptoms.

\begin{tabular}{|c|c|c|c|c|}
\hline \multirow{2}{*}{ Variables } & \multicolumn{2}{|c|}{ Psychological symptoms } & \multirow{2}{*}{ Total (\%) } & \multirow{2}{*}{$\begin{array}{l}\text { Chi-square } \\
\text { P value }\end{array}$} \\
\hline & Yes $(\%)$ & No $(\%)$ & & \\
\hline \multicolumn{5}{|l|}{ Occupation } \\
\hline Home-maker & $105(62.1)$ & 64 (37.9) & $169(100)$ & $\mathrm{X}^{2}=11.183$ \\
\hline $\begin{array}{l}\text { Working women } \\
\text { (Agricultural +Labourer) }\end{array}$ & $65(83.3)$ & $13(16.7)$ & 78 (100) & $\mathrm{p}=0.001 *$ \\
\hline Total & $170(68.8)$ & 77 (31.2) & 247 & \\
\hline
\end{tabular}

Table 5: Association of nature of dependency \& family type with psychological symptoms.

\begin{tabular}{|lllll|}
\hline Nature of dependency & \multicolumn{2}{l|}{ Psychological symptom } & Total & $\begin{array}{l}\text { Chi-square } \\
\text { p-Value }\end{array}$ \\
\hline & Yes (\%) & No (\%) & & $\begin{array}{l}\mathrm{X}^{2}=116.421 \\
\mathrm{p}<0.001^{*}\end{array}$ \\
\hline Self & $139(95.2)$ & $7(4.8)$ & $146(100)$ & \\
\hline Spouse & $22(33.3)$ & $44(66.7)$ & $66(100)$ & \\
\hline Family members & $9(25.7)$ & $26(74.3)$ & $35(100)$ & $\mathrm{X}^{2}=9.847$ \\
\hline Total & $170(68.8)$ & $77(31.2)$ & 247 & $\mathrm{p}=0.002^{*}$ \\
\hline Type of family & & & & \\
\hline Nuclear & $107(77)$ & $32(23)$ & $139(100)$ & \\
\hline Joint & $63(58.3)$ & $45(41.7)$ & $108(100)$ & 247 \\
\hline Total & $170(68.8)$ & $77(31.2)$ & & \\
\hline
\end{tabular}

\section{DISCUSSION}

A study conducted by Singh and Pradhan et al. ${ }^{8}$ in Delhi reported that $59.1 \%$ of postmenopausal women complained of muscle/ joint pain. Studies by Sagdeo et al. ${ }^{1}$ and Nusrat et al. $^{9}$ reported that the prevalence of muscle or joint pain were $60.4 \%$, and $66.74 \%$ respectively which was similar to the findings of the present study.

In another study done by Donald et al. ${ }^{10}$ in Gujarat it was reported that the women experienced all the three types of menopausal health problems-vasomotor, psychiatric and somatic. Somatic symptoms like tiredness and headache was experienced by majority of the respondents i.e. $88.4 \%$ and $74.8 \%$. Among the psychiatric problems, depressive episodes were experienced by $13.6 \%$ of the women. On the other hand, the percentages of subjects who experienced symptoms of anxiety, irritability and insomnia were $38.1 \%, 21.1 \%$ and $57.1 \%$ respectively. In a study done by Singh and Pradhan et al. ${ }^{11}$ It was reported that $38.1 \%$ postmenopausal women complained of palpitation.

A study by Nadia $\mathrm{J}$ et al. ${ }^{12}$ found that education level of the female, housewives and females belonging to low socioeconomic strata experienced the menopause associated vasomotor symptoms more and have been found to have important association with vasomotor symptoms of menopause. Low educational status was considered as high risk factor of vasomotor symptoms. Low literacy rate was associated with more psychological stresses leading to increase severity of hot flushes and night sweats.

In a cross-sectional study by Madhukumar $\mathrm{S}$ et al. ${ }^{13}$ it was reported that occupation, marital status had a significant impact on the health of postmenopausal women. Homemakers experience the menopause associated vasomotor symptoms more which was similar to the findings of present study.

Another study conducted by Alquiz et al. ${ }^{14}$ showed that females who had received higher education had less menopause related vasomotor symptoms. The females belonging to low socioeconomic strata are more likely to report vasomotor symptoms with increased severity as compared to females belonging to high socioeconomic strata.

A Study done by Sreelatha $\mathrm{S}$ et al. $^{15}$ found that the prevalence of urogenital symptoms was slightly more among women who underwent caesarean delivery $(21.1 \%)$ than the normal delivery group $(18.4 \%)$ however the observed difference was not statistically significant and no significant association was also noted with parity.

In another study by Karmakar et al. ${ }^{2}$ it was observed that symptoms were significantly associated with the number of children i.e. 2.97(1.25-7.04). However study by Susila et al. ${ }^{16}$ did not find any significant association between obstetric factors like parity, mode of delivery, with the urogenital symptoms. 
A study by Kaulagekar et al. ${ }^{17}$ reported that the respondents living in nuclear families faced significantly more $(\mathrm{p}<0.01)$ psychological symptoms as compared to those living in joint families which was similar to the present study finding.

\section{CONCLUSION}

Menopause is a normal physiological state in a woman's life. It is not a disease process. With the increase in life expectancy, the population of post-menopausal women and health issues related to post-menopause is substantially increasing. Efforts are needed to educate women by health workers or women organization to make them aware about various menopausal symptoms and clear their doubts \& fears.

\section{Funding: No funding sources}

Conflict of interest: None declared

Ethical approval: The study was approved by the Institutional Ethics Committee

\section{REFERENCES}

1. Sagdeo MM, Arora D. Menopausal symptoms: a comparative study in rural and urban women. J K Science. 2011;13(1):23-6.

2. Karmakar N, Majumdar S, Dasgupta A, Das S. Quality of life among menopausal women: A community-based study in a rural area of West Bengal. J Midlife Health. 2017;8(1):21-7.

3. Research on the menopause in the 1990s. Report of a WHO Scientific Group. World Health Organ Tech Rep Ser. Available at: http://www.ncbi.nlm.nih.gov/ pubmed/8942292. Accessed on 23 July 2020.

4. Unni J. Third consensus meeting of Indian Menopause Society (2008): A summary. J Midlife Health. 2010;1(1):43-7.

5. Introduction to overall health and quality of health in women. Available from: http://shodhganga.inflibnet. ac.in/bitstream/10603/129352/7/07_chap1.introducti on.pdf. Accessed on 20 July 2020.

6. Dutta R, Dcruze L, Anuradha R, Rao SRM. A Population Based Study on the Menopausal Symptoms in a Rural Area of Tamil Nadu, India. Journal of Clinical and Diagnostic Research. 2012(Suppl-2);6(4):597-601.

7. Census of India 2011 Odisha series-22 part xii-b district census handbook ganjam village and town wise Primary Census Abstract(PCA) directorate of census operations Odisha. Available at: https://cdn.s3waas.gov.in/s3496e05e1aea0a9c46558 00e8a7b9ea28/uploads/2016/09/2018032926.pdf. Accessed on 20 July 2020.

8. Singh A, Pradhan SK. Menopausal symptoms of postmenopausal women in a rural community of Delhi, India: A cross-sectional study. J Midlife Health. 2014;5(2):62-7.

9. Nusrat N, Nishat Z, Gulfareen H, Aftab M, Asia N. Knowledge, attitude and experience of menopause. J Ayub Med Coll Abbottabad. 2008;20(1):56-9.

10. Christian D, Kathad M, Bhavsar B. Sociodemographic characteristics of post- menopausal women of rural area of Vadodara district, Gujarat. Natl J Community. 2011;2(3):419-22.

11. Das N, Prasad Das B. Age of menopause and menopausal symptoms among women attending Gauhati Medical College and Hospital, Guwahati, Assam: A cross-sectional study. Sch J Appl Med Sci Sch J App Med Sci. 2015;3(7C):2621-9.

12. Jabeen N, Akmal S, Shabbir S, Mahmood M. Association of menopause related vasomotor symptoms with socio-demographic factors. Journal of Rawalpindi Medical College. 2015;19(3):235-8.

13. Madhukumar S, Gaikwad V. A community based study on perceptions about menopausal symptoms and quality of life of post-menopausal women in Bangalore rural. Int J Heal Sci Res. 2017;8:21-7.

14. Alquaiz JM, Siddiqui AR, Tayel SA, Habib FA. Determinants of severity of menopausal symptoms among Saudi women in Riyadh city. Climacteric. 2014;17(1):71-8.

15. Sreelatha AS, Hassan SH. Prevalence and pattern of direct gynecological morbidity among postmenopausal women aged above 50- a community study. 2017;5(4):21070-6.

16. Susila T, Roy G. Gynecological morbidities in a population of rural postmenopausal women in pondicherry: uncovering the hidden base of the iceberg. J Obstet Gynecol India. 2014;64(1):53-8.

17. Kaulagekar A. Age of menopause and menopausal symptoms among urban women in Pune, Maharashtra. J Obstet Gynecol India. 2011;61(3):323-6.

Cite this article as: Satapathy SP, Karmee N, Dash R. Prevalence of menopausal symptoms and its association with various factors among women in post menopausal age group: a cross-sectional study. Int J Reprod Contracept Obstet Gynecol 2020:9:3837-42. 